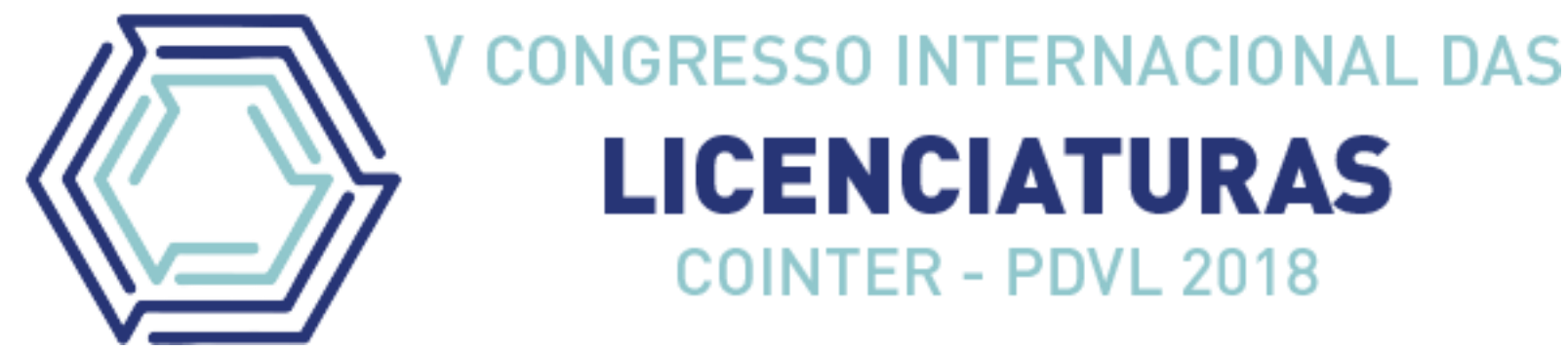

\title{
A APLICABILIDADE DO DRONE E DA IMPRESSORA 3D NO ENSINO DE MATEMÁTICA
}

\section{THE APPLICABILITY OF DRONE AND THE 3D EMPRESSOR IN THE EDUCATION OF MATHEMATICS}

Apresentação: Relato de Experiência

Lino Cardoso Assunção Filhol ${ }^{1}$; Roberto Arruda ${ }^{2}$.

DOI: https://doi.org/10.31692/2358-9728.VCOINTERPDVL.2018.00248

\section{Introdução}

O presente relatório é fruto do trabalho desenvolvido enquanto bolsista CNPQ/PIBIC na modalidade iniciação científica (IC), sob a orientação do professor Dr. Roberto Arruda e em cooperação com o laboratório de Matemática do IFPI Campos Teresina Central. A ideia central da pesquisa consiste em observar a potencialidade instrumental de equipamentos tecnológicos, em especial, a impressora 3D e o Drone. A globalização e o grande crescimento da indústria tecnológica, aliado ao grande processo de informatização das instituições de ensino público e privado, seja ela municipal estadual ou federal, proporcionam mudanças e aperfeiçoamento por parte dos futuros e atuais professores, no que se refere às inovações tecnológicas.

Diversas práticas educacionais vêm surgindo ao longo dos últimos anos que proporcionam uma nova visão da forma de se ensinar um conteúdo. Com o grande processo de informatização, essa visão mudou e foi necessário a implementação de novos meios de ensino, com o objetivo de uma educação mais moderna, mais abrangente e diversificada. Com esse objetivo, foi realizado um minicurso com a intenção de aplicar a utilização de materiais tecnológicos no ensino dos conteúdos matemáticos.

\section{Relato de Experiência}

O presente trabalho foi realizado no Instituto Federal de Tecnologia e Ciências de Teresina, Piauí, com graduandos de licenciatura em Matemática, alunos do ensino médio e Professores através do Programa Institucional de Bolsas de Iniciação Científica - PIBIC com o tema: Desenvolvimento de novas estratégias de ensino matemático com uso e aplicações das novas tecnologias disponíveis no laboratório de Ensino e modelagem de matemática do IFPI - Campos Teresina Central - unidade mestre de matemática, Drone, Impressora 3D e outros equipamentos. O Projeto teve por objetivo analisar e aplicar equipamentos com grande potencial de ensino nas aulas de matemática, como consequência do trabalho, foi realizado um minicurso na Semana de Matemática e Física (SEMAFIS) do IFPI - Campos Teresina Central nos dias 01, 02 e 03 do mês de agosto de 2018.

A princípio, fizemos a apresentação teórica dos instrumentos tecnológicos (Impressora 3D i3 Prusa e o Drone Fanton 3), explicamos os modelos e a forma de encontra-los no

\footnotetext{
${ }^{1}$ Licenciatura em Matemática, IFPI - Campus Teresina Central, linofilho08@gmail.com

${ }^{2}$ Curso, IFPI - Campus Teresina Central, robertoarruda@ifpi.edu.br.
} 
mercado. Depois, apresentamos a utilização correta dos equipamentos, com a devida segurança. Percebeu-se que os alunos e professores presentes se interessaram muito e tiraram várias duvidas sobre os equipamentos e sua utilização.

Em seguida, abordamos as diversas aplicações da Impressora 3D e do Drone, como por exemplo, o uso da impressora para imprimir sólidos geométricos ou objetos tridimensionais cujo processo de impressão utiliza-se elementos matemáticos (proporção e escala, movimentos geométricos e razão). Já o Drone é utilizado, muitas vezes, para monitoramento, como uma ferramenta para melhorar a criatividade e a experimentação em sala de aula, entre outros, com ele, foi apresentada a possibilidade do uso para a geometria plana, escalas, ou mapeamento de áreas.

Figura 1: Atividade. Teórica Fonte: Autor (2018)

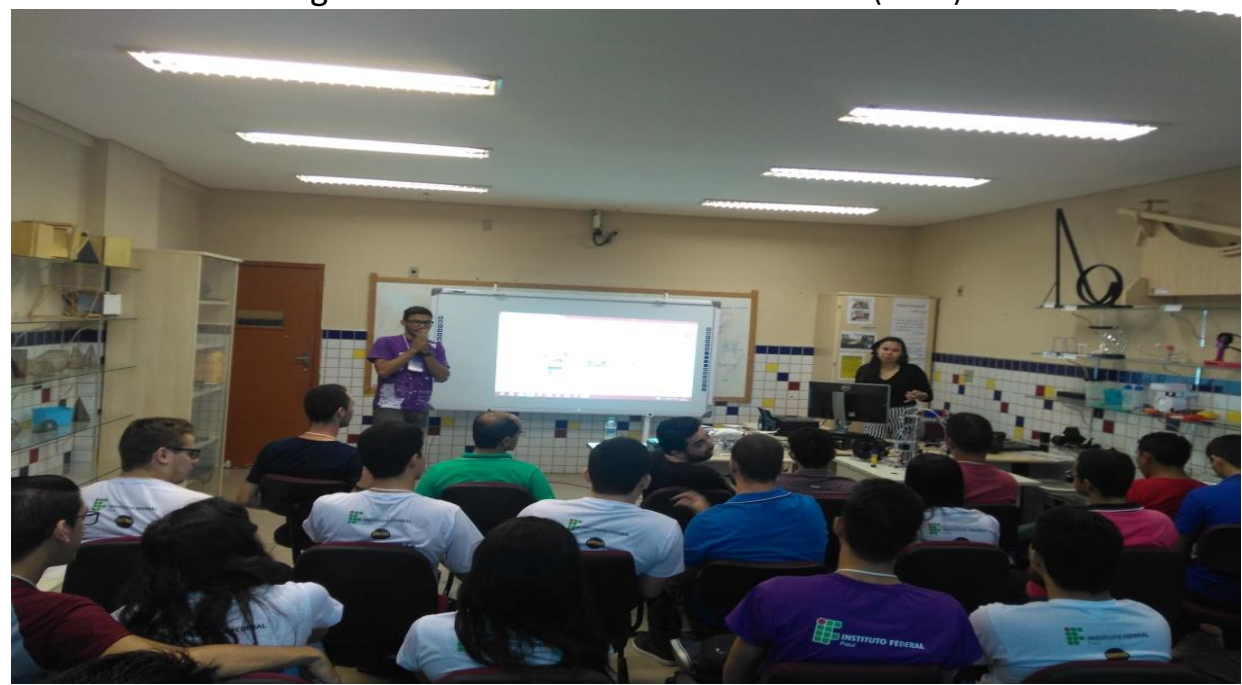

Por fim, fizemos a aplicação dos equipamentos. Os participantes montaram e controlaram o Drone baseado nas aplicações mencionados no início. Já a impressora, eles manusearam e viram o processo de impressão. O público se mostrou muito interessado e empenhado, tanto na parte teórica como na pratica, percebeu-se, também, que eles estavam bem animados na aplicação pratica.

Figuras 2 e 3: Atividades práticas do Drone e Impressora 3D, respectivamente. Fonte: Autor (2018).
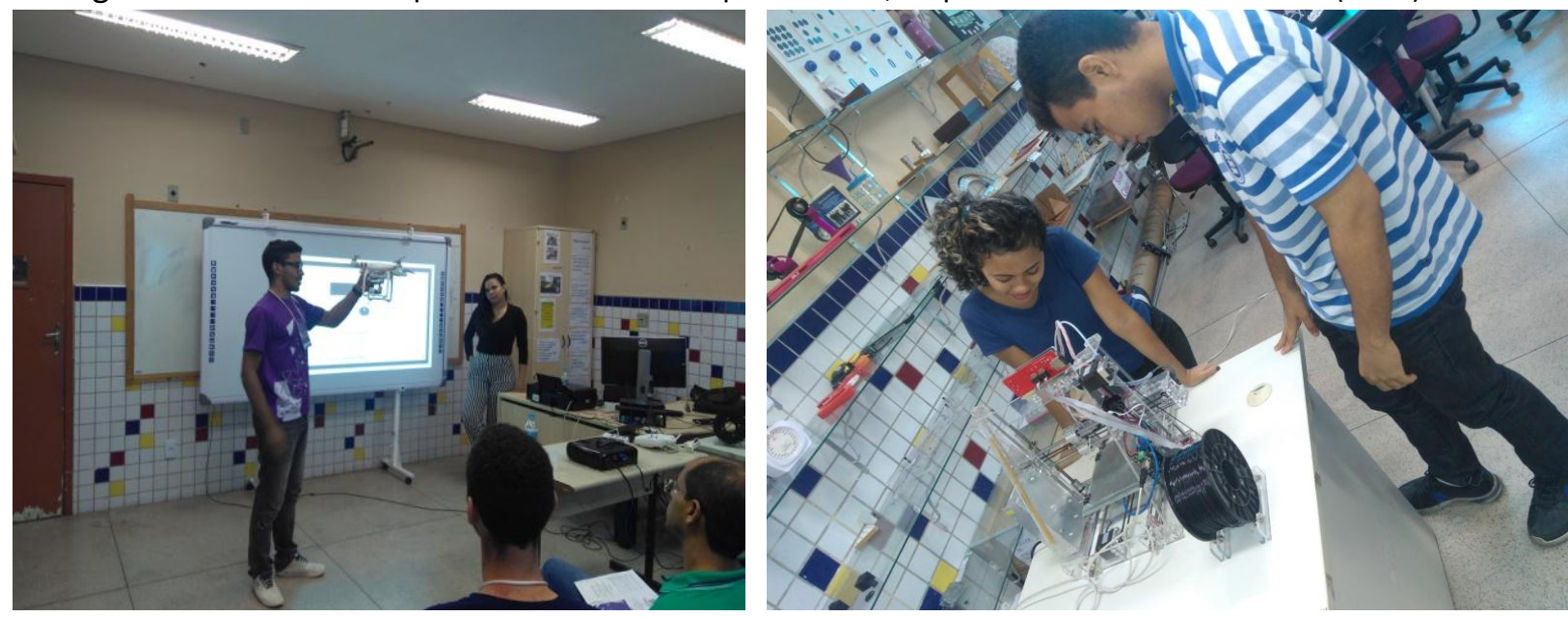
O minicurso foi dividido em dois dias, sendo que em cada dia foi apresentado um equipamento, realizado em duas aulas de duas horas, as quais foram divididas em duas partes, sendo duas horas para cada equipamento. Foi realizado para trinta e três participantes, entre discentes e docentes. Conseguimos mostrar na pratica a aplicação de assuntos matemáticos através dos equipamentos utilizados.

Figura 4: Participantes do minicurso. Fonte: Autor (2018)

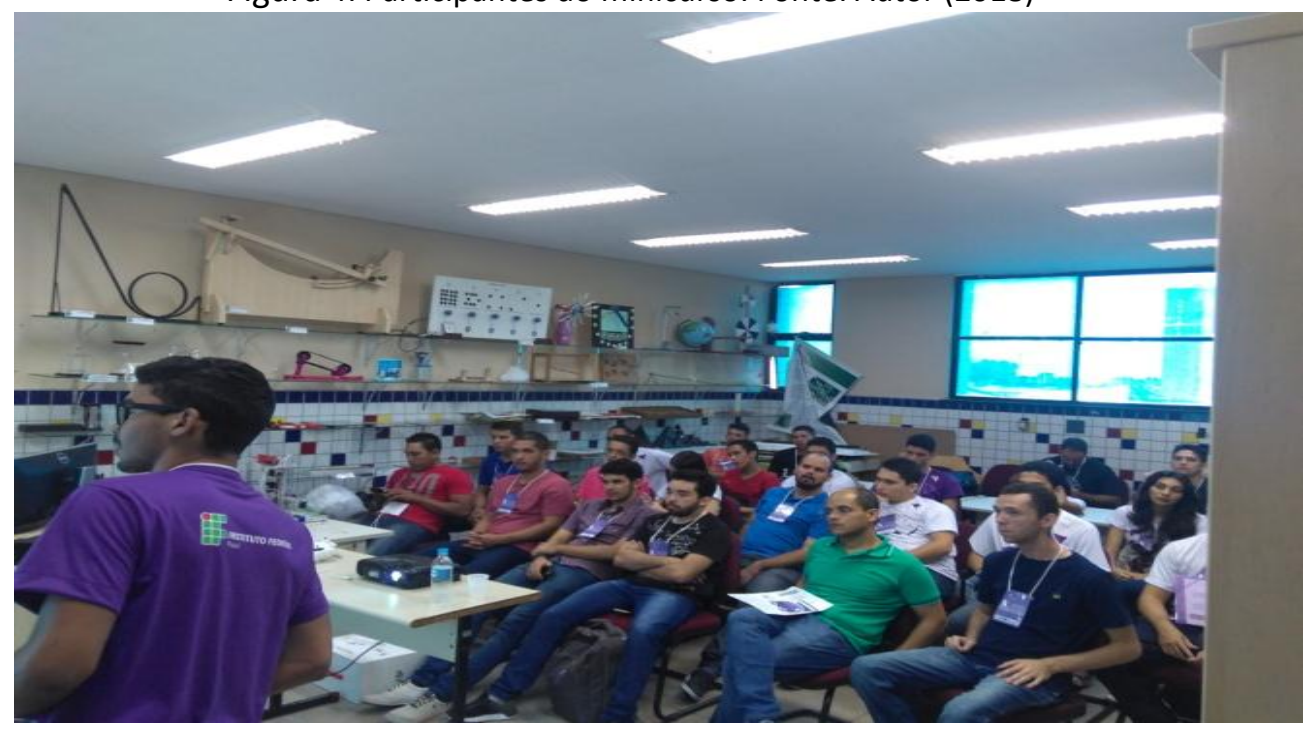

\section{Considerações}

O estudo realizado ajudará na ampliação da didática utilizada dentro da sala de aula, melhorando a aplicação de alguns conteúdos que a simples utilização de quadro, pincel e apagador não concede aos professores. Também, facilitaria a compreensão dos alunos de alguns conteúdos como: geometria espacial, escalas, função, dentre outros assuntos que não são tão simples de explicar usando os recursos comuns que foram citados.

A tecnologia se torna uma grande aliada da educação, já que se pode perceber uma maior interação por parte dos alunos com a disciplina, além de proporcionar uma maior facilidade por parte do docente para efetuar seu trabalho, proporcionando-lhe uma valorização maior da profissão e prazer na docência.

\section{Referências}

Sanmya Feitosa TAJRA. Informática na Educação São Paulo: Editora Érica, 2012.

PCNS. Parâmetros Nacionais Curriculares no CDU: 371.214, de 1997. Brasilia , 1997. 